\title{
REVIEW
}

\section{Follow-up of patients with thyroid cancer and antithyroglobulin antibodies: a review for clinicians}

\author{
Pedro Weslley Rosario1, Marina Carvalho Souza Côrtes ${ }^{2}$ and Gabriela Franco Mourão1 \\ 'Santa Casa de Belo Horizonte, Belo Horizonte, Minas Gerais, Brazil \\ 2Universidade Federal de Juiz de Fora, Juiz de Fora, Minas Gerais, Brazil
}

Correspondence should be addressed to P W Rosario: pedrowsrosario@gmail.com

\begin{abstract}
Antithyroglobulin antibodies (TgAb) are present in up to $25 \%$ of patients with differentiated thyroid carcinoma on initial postoperative assessment. Detectable concentrations of TgAb even below the manufacturer's cut-off can interfere with serum thyroglobulin (Tg) determination. When Tg is quantified using an immunometric assay (IMA) (hereafter referred to as Tg-IMA), this interference results in underestimated values of Tg. Although promising, more clinical trials evaluating the capacity of liquid chromatography/tandem mass spectrometry and of new assays to detect elevated $\mathrm{Tg}$ in patients with $\mathrm{TgAb}$ and structural disease are necessary, particularly when $\mathrm{Tg}$ is undetectable by a second-generation IMA (Tg-2GIMA). Neck ultrasonography (US) should be performed in patients submitted to total thyroidectomy and with negative Tg-IMA but with detectable TgAb more than 6 months after initial therapy. In patients treated with 1311, comparison of TgAb concentrations obtained before this treatment is useful to estimate the risk of disease and to guide the investigation. If initial assessment does not reveal any persistent tumor, the repetition of US is recommended while TgAb persist. Significant elevation of TgAb requires extended investigation. On the other hand, patients with negative Tg-IMA and US without abnormalities who exhibit a reduction $>50 \%$ in $\mathrm{TgAb}$ generally do not require investigation. Although $\mathrm{TgAb}$ can interfere with $\mathrm{Tg}$, the management and follow-up of patients submitted to total thyroidectomy with borderline $\operatorname{TgAb}$ can probably be the same as those recommended for patients without TgAb if Tg-2GIMA and US indicate an excellent response to therapy. Currently, the presence/ absence or the trend of TgAb levels cannot be considered in the follow-up of patients submitted to lobectomy.
\end{abstract}

\section{Introduction}

Thyroid autoantibodies are commonly measured for the diagnosis and follow-up of thyroid autoimmune diseases. In this case, antibodies other than antithyroglobulin antibodies (TgAb) are more relevant, namely antithyroperoxidase antibodies (TPOAb) in Hashimoto's thyroiditis and anti-TSH receptor antibodies (TRAb) in Graves' disease. $\mathrm{TgAb}$ are more important in the follow-up of thyroid cancer because of their potential interference with thyroglobulin (Tg) assay and their measurement is, therefore, necessary in situations in which $\mathrm{Tg}$ measurement 
is useful and requested. The most common situation is the follow-up of patients with differentiated thyroid carcinoma (DTC) after thyroidectomy in which Tg is a sensitive and specific tumor marker that is fundamental for assessment of the response to therapy and for the early detection of recurrences (Haugen et al. 2015, Lamartina et al. 2018, Pacini et al. 2018, Filetti et al. 2019, Haddad et al. 2020). However, up to $25 \%$ of patients with DTC have $\mathrm{TgAb}$ on initial postoperative assessment (Trimboli et al. 2017, Dekker et al. 2019, Zavala et al. 2019), the first occasion when serum $\mathrm{Tg}$ measurement is recommended (Haugen et al. 2015, Lamartina et al. 2018, Pacini et al. 2018, Filetti et al. 2019, Haddad et al. 2020).

\section{Measurement of TgAb in patients with DTC}

We report below some important aspects regarding the measurement of $\mathrm{TgAb}$ in patients with DTC:

According to current guidelines, different time points exist for the measurement of serum $\mathrm{Tg}$ after surgery in patients with DTC. As they can interfere with $\mathrm{Tg}$, the simultaneous measurement of $\mathrm{TgAb}$ is also recommended (Verburg et al. 2013, Haugen et al. 2015, Lamartina et al. 2018, Pacini et al. 2018, Filetti et al. 2019, Haddad et al. 2020). In patients with TgAb, the behavior of the concentration of these antibodies in subsequent measurements is a predictor of tumor recurrence, and in patients without these antibodies, although uncommon, appearance of TgAb during follow-up is possible (Carvalho et al. 2017, Cortês et al. 2018a, Reverter et al. 2020, Scappaticcio et al. 2020, Yin et al. 2020).

TgAb should be measured with immunoassays. In addition to the manufacturer cut-off (MCO), it is important to know the functional sensitivity (FS) of the assay. Reference values of $\mathrm{TgAb}$ are established to distinguish individuals with and without thyroid autoimmune disease. However, detectable concentrations of $\mathrm{TgAb}$ (i.e. above the FS) even below the MCO, called borderline, can interfere with serum $\mathrm{Tg}$ (Spencer et al. 2014). It is, therefore important, to know whether $\mathrm{TgAb}$ concentrations below the MCO are undetectable (i.e. < FS) or detectable (i.e. > FS).

As we will see subsequently, the behavior of $\operatorname{TgAb}$ is a predictor of persistent/recurrent disease after treatment. Obviously, the same assay must be used in order to compare $\mathrm{TgAb}$ concentrations. Clinicians must be aware of changes in the assay and, if that was the case, comparisons with previous concentrations are not possible. We also do not recommend the use of formulas for conversion between assays or comparison of the magnitude of $\mathrm{TgAb}$ elevation in relation to the MCO. The first measurement of $\mathrm{TgAb}$ with the new assay becomes the starting point for future comparisons.

The transient appearance of $\operatorname{TgAb}$ is not uncommon (Carvalho et al. 2017, Cortês et al. 2018a,b, Scappaticcio et al. 2020) and more frequently occurs after damage to the normal or tumor thyroid tissue or during treatment with immunomodulators; however, it may also have no apparent cause (Carvalho et al. 2017, Cortês et al. 2018a,b, Scappaticcio et al. 2020). Thus, in cases in which TgAb are detected for the first time without a concomitant increase of serum $\mathrm{Tg}$, the persistence of this finding should be confirmed before starting an investigation for structural disease with imaging methods.

Finally, in patients with apparent tumors but surprisingly with negative serum $\mathrm{Tg}$ measured by an immunometric assay (IMA) and with negative $\operatorname{TgAb}$, the latter can be measured with another assay, particularly in patients with lymphocytic thyroiditis on histology (Latrofa et al. 2012). If elevated $\mathrm{TgAb}$ are detected by another assay, their interference is the likely cause of negative $\mathrm{Tg}$; the behavior of $\operatorname{TgAb}$ concentrations measured by this assay can be useful for patient monitoring or for assessing the response to therapy.

\section{Interference of TgAb with $\mathrm{Tg}$}

Techniques and assays for the measurement of $\mathrm{Tg}$ are discussed comprehensively by Hoofnagle \& Roth (2013). Immunometric assays are currently the most widely used tests for the measurement of Tg; in these assays, the interference of $\mathrm{TgAb}$ results in underestimated and, in extreme cases, even undetectable values of $\mathrm{Tg}$ (i.e. false-negative $\mathrm{Tg}$ result) (Rosario et al. 2004a, Spencer et al. 2014) because the Tg-TgAb complex decreases the concentration of free $\mathrm{Tg}$, which is the fraction measured by IMA. Thus, patients with known structural disease and/or serum Tg-IMA concentrations that already indicate an incomplete biochemical response or the need for investigation according to current guidelines (Verburg et al. 2013, Haugen et al. 2015, Lamartina et al. 2018, Pacini et al. 2018, Filetti et al. 2019, Haddad et al. 2020) or the institutional protocol do not represent the main problem. The greatest challenge is patients with serum Tg-IMA concentrations suggestive of tumor absence in whom it is not possible to ensure whether this finding indicates complete remission or underestimated $\mathrm{Tg}$ due to the interference of $\mathrm{TgAb}$. 
The interference with serum $\mathrm{Tg}$ cannot be ruled out or ensured based on TgAb concentrations (Spencer et al. 2014). Detectable concentrations of TgAb even below the MCO can already interfere with serum Tg (Spencer et al. 2014), while the absence of interference may occasionally be observed even at concentrations much higher than the MCO (Rosario et al. 2004a,b, Spencer et al. 2014).

By mixing the patient's serum with TgAb to a solution with known $\mathrm{Tg}$ concentration, the $\mathrm{Tg}$ concentration obtained (i.e. recovered $\mathrm{Tg}$ ) is assumed to be $>80 \%$ of the expected concentration in the mixture (Tg recovery testing). When this occurs, that is, a recovery is 'appropriate', the probability of $\operatorname{TgAb}$ interference with serum Tg is lower but cannot be ruled out (Spencer et al. 1998, Rosario et al. 2004a,b). In fact, Tg recovery testing is not recommended in clinical practice to ensure that $\mathrm{TgAb}$ do not interfere with serum Tg (Verburg et al. 2013, Haugen et al. 2015, Pacini et al. 2018).

It is important to remember that, nowadays, $\mathrm{Tg}$ measurement is usually performed with second-generation IMA (Tg-2GIMA), that is with a FS $<0.2 \mathrm{ng} / \mathrm{mL}$, in contrast to first-generation IMA whose FS was approximately $1 \mathrm{ng} / \mathrm{mL}$. Measurement of Tg by liquid chromatography/ tandem mass spectrometry (Tg-LC/MS) has been evaluated in patients with $\mathrm{TgAb}$; however, when serum Tg-2GIMA was undetectable, Tg-LC/MS was also negative in many patients with structural disease (Spencer et al. 2014, Netzel et al. 2015, Azmat et al. 2017, Guastapaglia et al. 2020). A first study showed that Tg-LC/MS was undetectable in 12/20 patients with $\operatorname{TgAb}$ and persistent/recurrent disease who had serum Tg-2GIMA $\leq 0.1 \mathrm{ng} / \mathrm{mL}$ (Spencer et al. 2014). A second study included 27, 20 and 18 patients with $\mathrm{TgAb}$ and structural disease in whom serum Tg-2GIMA was undetectable ( $\leq 0.1,0.1$ and $0.15 \mathrm{ng} / \mathrm{mL}$, respectively). $\mathrm{Tg}$-LC/MS was undetectable in 21/27, 17/20 and 15/18 of these patients, respectively (Netzel et al. 2015). In two other studies including a smaller number of patients with $\mathrm{TgAb}$ and structural disease and serum Tg-2GIMA $\leq 0.1 \mathrm{ng} / \mathrm{mL}$, Tg-LC/MS was undetectable in 5/9 patients (Azmat et al. 2017, Guastapaglia et al. 2020). Finally, Kushnir et al. (2013) observed Tg-LC/MS $>0.5 \mathrm{ng} / \mathrm{mL}$ in only $23 \%$ of 71 samples with $\mathrm{TgAb}$ and $\mathrm{Tg}$-IMA $<0.5 \mathrm{ng} / \mathrm{mL}$.

Thyroglobulin measured by RIA (Tg-RIA) is able to detect most cases of disease in patients with $\mathrm{TgAb}$ and the presence of disease is unlikely when Tg-RIA is undetectable (Rosario et al. 2004a,b, Spencer et al. 2014, Netzel et al. 2015). Unfortunately, Tg-RIA is not easily accessible and it is important to know that false-positive results are possible in patients with $\mathrm{TgAb}$. Recently, a new competitive immunoassay using polyclonal antibodies was also able to detect serum $\mathrm{Tg}$ in patients with $\mathrm{TgAb}$ and structural disease who had negative Tg-IMA and Tg-LC/MS (Guastapaglia et al. 2020).

In conclusion, more clinical trials are needed to assess the real capacity of LC/MS and of new assays to detect elevated serum $\mathrm{Tg}$ in patients with $\mathrm{TgAb}$ and structural disease, particularly in those with undetectable or very low Tg-2GIMA. In addition, these assays that are potentially more resistant to interference of $\mathrm{TgAb}$ currently have a lower FS than ${ }^{2 G I M A . ~ T h u s, ~ e v e n ~ i n ~ t h e ~ a b s e n c e ~ o f ~}$ interference of $\mathrm{TgAb}$, serum $\mathrm{Tg}$ that is undetectable by these assays may indicate a higher risk of disease than that observed for an excellent response defined with Tg-2GIMA.

\section{Clinical management of patients with DTC and $\operatorname{TgAb}$}

\section{Patients submitted to total thyroidectomy with negative serum Tg-IMA and persistence of TgAb more than 6 months after initial therapy}

\section{Initial assessment}

Neck ultrasonography (US) can detect persistent disease after initial therapy even in patients with negative serum Tg-IMA and negative serum TgAb, and its use is even more justified in patients with TgAb. One study evaluated 120 non-high-risk patients with apparently complete tumor resection and post-therapy whole-body scanning (RxWBS) not revealing ectopic uptake. Clinical examination and serum Tg-IMA were negative for persistent tumors 8-12 months after radioiodine but the patients had elevated TgAb. Neck US also detected metastases in four patients (3.5\%) (Rosario et al. 2016).

If $\operatorname{TgAb}$ were measured before radioiodine administration, comparison of concentrations is useful to estimate the risk of persistent/recurrent disease. In a study evaluating 56 patients with undetectable serum Tg-IMA and without apparent disease but with elevated $\mathrm{TgAb}$ 6-12 months after radioiodine, a reduction $>50 \%$ in $\mathrm{TgAb}$ concentration compared to that obtained before ${ }^{131}$ I was associated with the absence of recurrence, while a modest reduction $(<50 \%)$ implied a risk of recurrence of $19 \%$. Among patients with $\mathrm{TgAb}$ elevation, 37\% developed recurrences (Kim et al. 2008). A larger study investigated 116 patients who also had negative serum Tg-IMA and no apparent tumor, including neck US without abnormalities but who continued to have elevated TgAb 8-12 months after radioiodine. In that study, a reduction $>50 \%$ in $\mathrm{TgAb}$ concentration compared to that obtained before ${ }^{131}$ I was
(C) 2021 Society for Endocrinology Published by Bioscientifica Ltd. Printed in Great Britain 
associated with a risk of structural disease of only $1.8 \%$, while a lower $\mathrm{TgAb}$ reduction resulted in a risk of $14.3 \%$. Metastases were detected in 24\% of patients with TgAb elevation (Rosario et al. 2016). Using that comparison (TgAb before and after ablation with ${ }^{131} \mathrm{I}$ ), patients without significant $\mathrm{TgAb}$ reduction exhibit a higher risk of tumor persistence/recurrence than those with a reduction $>50 \%$ (Kim et al. 2008, Rosario et al. 2016, Ernaga-Lorea et al. 2018, Trimboli et al. 2017, Sun et al. 2020). In fact, instead of grouping patients with declining and stable TgAb (Haugen et al. 2015, Lamartina et al. 2018, Filetti et al. 2019), other authors consider that TgAb stability deserves greater attention than a significant reduction (Verburg et al. 2013, Haddad et al. 2020).

The probability of detection of structural disease in patients with elevated $\mathrm{TgAb}$ but negative serum Tg-IMA appears also to be influenced by the individual risk of tumor persistence/recurrence (Kim et al. 2008, Rosario et al. 2016). In low-risk patients submitted only to total thyroidectomy, neck US is sufficient during initial assessment, reserving additional investigation with other imaging methods (which can include WBS after empirical 131I activity) only for cases without the expected long-term reduction of TgAb (Matrone et al. 2018, Zavala et al. 2019).

The presence of lymphocytic thyroiditis on histology suggests that previous thyroid autoimmunity is the cause of $\mathrm{TgAb}$ persistence; thus, the probability that this finding indicates tumor persistence/recurrence is low (Hsieh \& Wang 2014, Woeber 2016). However, many studies do not confirm the lower risk of structural disease in patients with persistent $\operatorname{TgAb}$ after total thyroidectomy in the case of lymphocytic thyroiditis (Chung et al. 2002, Kim et al. 2008, Lupoli et al. 2015, Carvalho et al. 2017). Thus, although lymphocytic thyroiditis may be associated with the persistence of elevated $\mathrm{TgAb}$ for a longer period of time, in principle, the management of patients with persistent $\mathrm{TgAb}$ after initial therapy should not be different in the presence of this condition.

Table 1 shows the initial assessment suggested for patients submitted to total thyroidectomy (with or without ${ }^{131}$ I) who exhibit negative serum Tg-IMA and neck US without abnormalities but who have TgAb more than 6 months after initial therapy.

\section{Late follow-up}

When initial assessment of patients submitted to total thyroidectomy (with or without 131I) does not reveal persistent disease, these patients progress to a relevant and sustained increase of serum Tg-IMA during follow-up, tumor recurrence should be investigated (initially by neck US) (Haugen et al. 2015, Lamartina et al. 2018, Pacini et al. 2018, Filetti et al. 2019, Haddad et al. 2020). This applies even more in the presence of detectable TgAb. On the other hand, patients who initially have detectable TgAb but that become undetectable during follow-up accompanied by negative serum $\mathrm{Tg}$ and recent neck US showing no abnormalities are followed-up as recommended for the 'excellent response to therapy' category (Haugen et al. 2015, Lamartina et al. 2018, Pacini et al. 2018, Filetti et al. 2019, Haddad et al. 2020).

Table 1 Suggested initial assessment of patients (Haugen et al. 2015, Pacini et al. 2018, Lamartina et al. 2018, Filetti et al. 2019) submitted to total thyroidectomy and with TgAb more than 6 months after initial therapy who have negative Tg-IMA and neck US without abnormalities.

\begin{tabular}{|c|c|}
\hline $\begin{array}{l}\text { Initial risk } \\
\text { stratification }\end{array}$ & Investigation (in addition to neck US) \\
\hline Low risk & $\begin{array}{l}\text { Generally, no investigation is necessary; however, consider other } \\
\text { imaging methods }{ }^{a} \text { if tumor }>4 \mathrm{~cm} \text { with increase } \text { of }^{\text {TgAb. }}\end{array}$ \\
\hline Intermediate risk & $\begin{array}{l}\text { Significant reduction of TgAbc: no investigation is necessary. } \\
\text { No significant reductionc or increase }{ }^{b} \text { of TgAb: obtain DxWBS or RxWBS } \\
\text { if the first RxWBS showed ectopic cervical uptake. If not or WBS } \\
\text { negative, consider other imaging methodsa, especially in the case of } \\
\text { aggressive histological subtype or increaseb of TgAb. }\end{array}$ \\
\hline High risk & $\begin{array}{l}\text { Obtain DxWBS or RxWBS if first RxWBS showed ectopic uptake. If not } \\
\text { or WBS negative, consider (if significant reductionc of TgAb) or obtain } \\
\text { (if no significant reductionc or if increase }{ }^{b} \text { of TgAb) other imaging } \\
\text { methods if not performed previously. }\end{array}$ \\
\hline
\end{tabular}

Initial target of TSH when investigation does not reveal persistent disease

TSH 0.5-2 mIU/L if significant reductionc of $\mathrm{TgAb}$

TSH 0.1-0.5 mIU/L if no significant reductionc or if increase ${ }^{b}$ of TgAb

TSH 0.1-0.5 mIU/L if significant reductionc of TgAb $\mathrm{TSH} \leq 0.1 \mathrm{mIU} / \mathrm{L}$ if no significant reductionc $^{c}$ or if increase ${ }^{b}$ of TgAb

aSuch as chest $C$ and FDG-PET/CT.

bIncrease (confirmed) of TgAb concentration compared to that obtained before radioiodine.

'Reduction $>50 \%$ of TgAb concentration compared to that obtained before radioiodine.

DxWBS, diagnostic whole-body scanning; RxWBS, post-therapy whole-body scanning; TgAb, antithyroglobulin antibodies; Tg-IMA, thyroglobulin measured by immunometric assay; US, ultrasonography. 
In patients submitted to total thyroidectomy (with or without 131I) without persistent disease, the behavior of $\mathrm{TgAb}$ is a predictor of tumor recurrence if the patient continues to show negative serum Tg-IMA and elevated TgAb. We consider periodic repetition of neck US appropriate in the case of persistence of $\operatorname{TgAb}$ and an excellent response to therapy, therefore, cannot be characterized. Significant TgAb elevation is associated with a higher risk of structural disease and requires extended investigation if neck US does not reveal tumor recurrence (Kim et al. 2008, Hsieh \& Wang 2014, Rosario et al. 2016, Ernaga-Lorea et al. 2018, Trimboli et al. 2017, Lee et al. 2020, Sun et al. 2020). However, before this investigation with other imaging methods, it would be interesting to confirm the persistence of TgAb elevation, which would only be considered significant if the increase in concentrations is higher than 50\%. On the other hand, patients with negative serum Tg-IMA and neck US without abnormalities but a reduction $>50 \%$ in $\mathrm{TgAb}$ concentrations are at a low risk of structural disease (Kim et al. 2008, Hsieh \& Wang 2014, Rosario et al. 2016, ErnagaLorea et al. 2018, Trimboli et al. 2017, Lee et al. 2020, Sun et al. 2020) and do not require additional investigation. Finally, the risk of structural disease appears to be higher in patients with a modest reduction or long-term stability of $\mathrm{TgAb}$ concentrations compared to those exhibiting a significant reduction (Kim et al. 2008, Hsieh \& Wang 2014, Rosario et al. 2016, Ernaga-Lorea et al. 2018, Trimboli et al. 2017, Sun et al. 2020). Also regarding the late follow-up, not all authors group patients with declining and stable TgAb (Haugen et al. 2015, Lamartina et al. 2018, Filetti et al. 2019), considering that TgAb stability is a matter of greater concern in terms of the risk of tumor recurrence (Verburg et al. 2013, Haddad et al. 2020).
Table 2 suggests a follow-up of patients submitted to total thyroidectomy (with or without 131I) and without persistent disease on initial assessment while continuing to show TgAb, negative serum Tg-IMA and neck US without abnormalities. In these patients, the degree of TSH suppression ( $\leq 0.1,0.1$ to 0.5 , or 0.5 to $2 \mathrm{mIU} / \mathrm{L}$ ) should be defined considering (i) the behavior of $\operatorname{TgAb}$ (significant reduction, stability, significant increase) and (ii) risk classification (low/intermediate or high), in addition to (iii) exposure time and risks associated with suppression (individually).

\section{Patients submitted to total thyroidectomy, with serum Tg-2GIMA and imaging method indicating excellent response to therapy, but with borderline TgAb}

It is known that borderline concentrations of $\mathrm{TgAb}$ can interfere with serum $\mathrm{Tg}$ (Spencer et al. 2014). However, this interference is less common compared to elevated $\mathrm{TgAb}$ concentrations (i.e. > MCO) and does not result in undetectable serum Tg-2GIMA in most cases (Spencer et al. 2014).

The risk of structural disease appears to be low in patients with serum Tg-2GIMA and neck US suggesting an excellent response to therapy, even in the presence of borderline TgAb. In a small initial series, none of the 4 to 12 patients (depending on the TgAb assay) with undetectable stimulated Tg-IMA and borderline TgAb had apparent disease on US or RxWBS (Latrofa et al. 2016). In another study, only $1 / 65$ patients $(1.5 \%)$ with borderline TgAb, but with serum Tg-2GIMA $\leq 0.2 \mathrm{ng} / \mathrm{mL}$ and a normal US at the time of ablation, had metastases on RxWBS (lymph nodes). This frequency was similar to that observed in 157 patients

Table 2 Suggested follow-up of patients (Haugen et al. 2015, Pacini et al. 2018, Lamartina et al. 2018, Filetti et al. 2019) submitted to total thyroidectomy (with or without 131I) with negative Tg-IMA but with TgAb more than 6 months after initial therapy, in whom recommended imaging methods did not detect persistent tumor.

Patients

All

Low or intermediate risk

High risk
Investigation while positive TgAb and negative serum Tg-IMA persist

Tg, TgAb, biannual clinical examination; annual neck US. Reductiona of TgAb: no additional investigation.

Increaseb of TgAb: obtain neck US and, if negative, other imaging methodsc if not performed previously. In the case of intermediate risk, consider repeating these exams if performed > 1 year.

Stable TgAbd: consider (low risk) or obtain (intermediate risk) other imaging methodsc if not performed previously. Consider repeating these exams if performed $>2$ years.

Stable TgAb or increaseb: obtain neck US and, if negative, other imaging methodsc if not performed previously. Consider repeating these exams if > 1 year (if increase) or $>2$ years (if stable).

a $>50 \%$ compared to the concentration of the last assessment that excluded structural disease.

b $>50 \%$ compared to the concentration of the last assessment that excluded structural disease.

cSuch as chest CT and FDG-PET/CT. In patients not treated with 1311, consider radioactive iodine therapy obtaining RxWBS.

dRecommended management in the case of stable TgAb $\geq 1$ year after the last assessment that excluded structural disease.

RxWBS, post-therapy whole-body scanning; TgAb, antithyroglobulin antibodies; Tg-IMA, thyroglobulin measured by immunometric assay; US, ultrasonography.

https://erc bioscientifica com

https://doi.org/10.1530/ERC-21-0012 (c) 2021 Society for Endocrinology Published by Bioscientifica Ltd. Printed in Great Britain 
with undetectable $\operatorname{TgAb}(1.3 \%)$ (Cortês et al. 2018). The same study found no difference in the frequency of structural recurrence when 156 patients with borderline $\mathrm{TgAb}$ and 420 patients with undetectable TgAb but normal neck US and serum Tg-2GIMA $\leq 0.2 \mathrm{ng} / \mathrm{mL} 12-18$ months after ablation were compared (Cortês et al. 2018). A third study showed that all 230 patients evaluated at the time of ablation with ${ }^{131}$ I had TgAb concentration > FS of the method, including 175 patients with concentrations $<$ MCO (borderline). After initial therapy, 139 of these patients had unstimulated Tg-IMA $\leq 1 \mathrm{ng} / \mathrm{mL}$, only two had persistent structural disease, and none of the patients developed recurrence (Dekker et al. 2019). Evaluating serum Tg-2GIMA, another study demonstrated an excellent negative predictive value (98\%) of $\mathrm{Tg}<0.15 \mathrm{ng} / \mathrm{mL}$ after total thyroidectomy and 131 I in 228 patients with detectable TgAb, masking only two cases of lymph node metastases (sensitivity of $87 \%$ ) (Giovanella et al. 2018, 2019). The rare cases of disease not detected clinically or by neck US, in which borderline $\operatorname{TgAb}$ led to such a significant interference that resulted in negative Tg-2GIMA, may still be suspected based on serum Tg-IMA or TgAb elevation in subsequent measurements (Cortês et al. 2018).

The adoption of FS instead of MCO for the definition of positive $\mathrm{TgAb}$ results in the reclassification of a large number of patients from excellent to indeterminate response to therapy, as established in current guidelines (Haugen et al. 2015, Lamartina et al. 2018, Pacini et al. 2018, Filetti et al. 2019). According to these guidelines, this change also implies the execution of more imaging methods, more frequent consultations, and the need for some degree of TSH suppression (Haugen et al. 2015, Lamartina et al. 2018, Pacini etal. 2018, Filetti etal.2019). The number of affected patients and the consequences of adopting FS instead of MCO for the definition of positive $\operatorname{Tg} \mathrm{Ab}$, including economic consequences and false-positive results, must be considered.

In clinical practice, the management and follow-up of patients submitted to total thyroidectomy (with or without ${ }^{131}$ I) with borderline TgAb may probably be the same as those recommended for patients with undetectable TgAb if Tg-2GIMA and neck US indicate an excellent response to therapy (Cortês et al. 2018).

\section{Patients submitted to total thyroidectomy with de novo appearance of TgAb and negative serum Tg-IMA}

Approximately $5 \%$ of patients with initially undetectable $\mathrm{TgAb}$ may develop detectable TgAb during follow-up

(c) 2021 Society for Endocrinology Published by Bioscientifica Ltd. Printed in Great Britain
(Carvalho et al. 2017, Cortês et al. 2018, Scappaticcio et al. 2020, Yin et al. 2020) but this elevation is transient in many of these patients (Carvalho et al. 2017, Cortês et al. 2018, Scappaticcio et al. 2020). Thus, as mentioned previously, the confirmation of $\mathrm{TgAb}$ detection is recommended in the case of de novo appearance of $\mathrm{TgAb}$ and persistence of negative serum Tg-IMA. If confirmed, neck US should be obtained and, if it does not reveal recurrence, the follow-up suggested in Table 2 can be adopted for these cases.

\section{Behavior of $\mathrm{TgAb}$ and tumor recurrence in patients submitted to lobectomy}

The persistence of an entire thyroid lobe may prevent the expected reduction of $\mathrm{TgAb}$ in the absence of a tumor, as suggested by the higher frequency of elevated $\mathrm{TgAb}$ in disease-free patients submitted to lobectomy vs those treated by total thyroidectomy (22.7\% vs $9 \%$ ) (Rosario et al. 2004b). Moreover, as an indication that even TgAb elevation can occur, Cho et al. (2018) reported a mean ratio of 1.89 between $\mathrm{TgAb}$ concentrations measured 2 years and 1 year after lobectomy in patients without residual tumor. In the same study, 2 years after lobectomy, the frequency of elevated $\operatorname{TgAb}$ was surprisingly higher in patients without tumor recurrence $(10.6 \%$ vs $0 \%)$. The behavior of $\mathrm{TgAb}$ also does not seem to predict structural disease. In the study of Cho et al. (2018), the mean ratio between $\mathrm{TgAb}$ concentrations measured 2 years and 1 year after lobectomy was 1.04 in patients who developed tumor recurrence, indicating the absence of $\operatorname{TgAb}$ elevation. None of the patients with recurrence had elevated TgAb 2 years after surgery. The only case of recurrence detected by Ritter et al. (2020) among 18 patients with elevated $\mathrm{TgAb}$ after lobectomy exhibited a surprising reduction of $\mathrm{TgAb}$ concentrations (from 1534 to $276 \mathrm{IU} / \mathrm{mL}$ ) at the time of detection of lymph node metastasis. In fact, a recent consensus (Pacini et al. 2018) highlights that 'the presence/absence and/or the trend of $\mathrm{TgAb}$ levels cannot be considered in the follow-up of patients submitted to lobectomy, due to the presence of the residual lobe'.

$\mathrm{Tg}$ in the needle washout of fine-needle aspiration of suspicious lymph nodes from patients with $\mathrm{TgAb}$

Some studies reported lower $\mathrm{Tg}$ concentrations in the needle washout of fine-needle aspiration (Tg-FNA) of metastatic lymph nodes and a lower sensitivity of Tg-FNA in patients with elevated $\operatorname{TgAb}$ compared to patients 
without TgAb (Jeon et al. 2013, Jo et al. 2015, Shin et al. 2015, Martins-Costa et al. 2017). Interestingly, this eventual reduction of Tg-FNA would not be explained by the presence of $\mathrm{TgAb}$ in the aspirate (Martins-Costa et al. 2017). Tg-FNA combined with cytology should be obtained from suspicious lymph nodes of patients with $\mathrm{TgAb}$ since many cases exhibit a positive result; in these patients with $\mathrm{TgAb}$ and undetectable serum $\mathrm{Tg}$, lower concentrations of Tg-FNA should be valued. However, considering that false-negative Tg-FNA results may be more frequent in patients with elevated $\mathrm{TgAb}$, other methods could eventually be used if the suspicion of lymph node metastasis is high.

\section{Other parameters for disease assessment after initial therapy in patients with TgAb}

The measurement of Tg mRNA in blood might be useful in patients without thyroid remnants (Boldarine et al. 2010). A study using a cut-off of $5.51 \mathrm{pg} \mathrm{Tg}$ mRNA/ $\mu \mathrm{g}$ RNA identified 13/14 patients with structural disease that had unstimulated serum $\mathrm{Tg}<1 \mathrm{ng} / \mathrm{mL}$ but elevated $\mathrm{TgAb}$, including seven patients who also had stimulated $\mathrm{Tg}<1 \mathrm{ng} / \mathrm{mL}$ during hypothyroidism (Boldarine et al. 2010). In contrast, patients free of disease were negative for circulating $\mathrm{Tg}$ mRNA, including six patients with $\mathrm{TgAb}$ (Boldarine et al. 2010). However, the measurement of $\mathrm{Tg}$ mRNA in blood has not been used in clinical practice because of a range of technical limitations, commercial unavailability, laborious execution, and the lack of clearly defined cut-off values.

Knowing the molecular alterations of the tumor, the detection of these alterations in peripheral blood of patients after treatment would indicate the presence of residual tumor (Cradic et al. 2009, Lee et al. 2013, Xiao et al. 2020). However, sensitivity might be limited, many of these molecular alterations are not specific for thyroid carcinomas, and clinical validation studies are necessary (Xiao et al. 2020).

\section{Conclusions}

Since they can interfere with serum $\mathrm{Tg}$, simultaneous measurement of $\mathrm{TgAb}$, which are present in up to $25 \%$ of patients with DTC on initial postoperative assessment, is recommended.

Detectable concentrations (i.e. above the FS of the assay) of $\mathrm{TgAb}$, even below the MCO, can interfere with $\mathrm{Tg}$. When measured with an IMA, the currently most widely used assay, this interference results in underestimated or, in extreme cases, undetectable values of Tg. Although promising, more clinical trials evaluating the real capacity of LC/MC and of new assays to detect elevated $\mathrm{Tg}$ in patients with $\mathrm{TgAb}$ and structural disease are necessary, particularly in those with undetectable or very low Tg-2GIMA.

Neck US should be performed in patients submitted to total thyroidectomy and with negative Tg-IMA in whom TgAb persist for more than 6 months after initial therapy. In patients treated with ${ }^{131}$ I, the comparison of $\mathrm{TgAb}$ concentrations obtained before this treatment is useful to estimate the risk of persistent/recurrent disease and to guide the investigation. On the other hand, US is initially sufficient in low-risk patients treated only with total thyroidectomy. If initial assessment does not reveal persistent disease, periodic repetition of US is recommended while $\operatorname{TgAb}$ persist, and the behavior of these antibodies is a predictor of tumor recurrence. Significant elevation requires extended investigation if US does not reveal recurrence. On the other hand, patients with persistently negative Tg-IMA and US without abnormalities but with a reduction $>50 \%$ in $\mathrm{TgAb}$ generally do not require additional investigation. Finally, the risk of structural disease appears to be higher in patients with a modest reduction or stability of $\mathrm{TgAb}$ when compared to those exhibiting a significant reduction.

Although $\mathrm{TgAb}$ can interfere with $\mathrm{Tg}$, in clinical practice, the management and follow-up of patients submitted to total thyroidectomy with borderline $\mathrm{TgAb}$ can probably be the same as those recommended for patients without $\mathrm{TgAb}$, given that Tg-2GIMA and US indicate an excellent response to therapy.

Currently, 'the presence/absence and/or the trend of TgAb levels cannot be considered in the follow-up of patients submitted to lobectomy' (Pacini et al. 2018).

Tg-FNA combined with cytology should be obtained from suspicious lymph nodes of patients with $\mathrm{TgAb}$ but concentrations may be lower and/or false-negative results may be more frequent.

\section{Declaration of interest}

The authors declare that there is no conflict of interest that could be perceived as prejudicing the impartiality of this review.

\section{Funding}

This work was supported by the National Council for Scientific and Technological Development (CNPq). (c) 2021 Society for Endocrinology Published by Bioscientifica Ltd. Printed in Great Britain 


\section{Author contribution statement}

All authors have contributed to study design, study conduct, data management, data analysis,data interpretation,manuscript writing,manuscript review and approval.

\section{References}

Azmat U, Porter K, Senter L, Ringel MD \& Nabhan F 2017 Thyroglobulin liquid chromatography-tandem mass spectrometry has a low sensitivity for detecting structural disease in patients with antithyroglobulin antibodies. Thyroid 27 74-80. (https://doi.org/10.1089/thy.2016.0210)

Boldarine VT, Maciel RM, Guimarães GS, Nakabashi CC, Camacho CP, Andreoni DM, Mamone Mda C, Ikejiri ES, Kasamatsu TS, Crispim F, et al. 2010 Development of a sensitive and specific quantitative reverse transcription-polymerase chain reaction assay for blood thyroglobulin messenger ribonucleic acid in the follow-up of patients with differentiated thyroid carcinoma. Journal of Clinical Endocrinology \& Metabolism 95 1726-1733. (https://doi.org/10.1210/jc.2009-1354)

Carvalho MS, Rosario PW, Mourão GF \& Calsolari MR 2017 Chronic lymphocytic thyroiditis does not influence the risk of recurrence in patients with papillary thyroid carcinoma and excellent response to initial therapy. Endocrine 55 954-958. (https://doi.org/10.1007/ s12020-016-1185-1)

Cho JW, Lee YM, Lee YH, Hong SJ \& Yoon JH 2018 Dynamic risk stratification system in post-lobectomy low-risk and intermediaterisk papillary thyroid carcinoma patients. Clinical Endocrinology $\mathbf{8 9}$ 100-109. (https://doi.org/10.1111/cen.13721)

Chung JK, Park YJ, Kim TY, So Y, Kim SK, Park DJ, Lee DS, Lee MC \& Cho BY 2002 Clinical significance of elevated level of serum antithyroglobulin antibody in patients with differentiated thyroid cancer after thyroid ablation. Clinical Endocrinology 57 215-221 (https://doi.org/10.1046/j.1365-2265.2002.01592.x).

Côrtes MCS, Rosario PW, Oliveira LFF \& Calsolari MR 2018a Clinical impact of detectable antithyroglobulin antibodies Below the reference limit (borderline) in patients with papillary thyroid carcinoma with undetectable serum thyroglobulin and normal neck ultrasonography After ablation: A prospective study. Thyroid $\mathbf{2 8}$ 229-235 (https://doi.org/10.1089/thy.2017.0350).

Côrtes MCS, Rosario PW, Mourão GF \& Calsolari MR $2018 b$ Influence of chronic lymphocytic thyroiditis on the risk of persistent and recurrent disease in patients with papillary thyroid carcinoma and elevated antithyroglobulin antibodies after initial therapy. Brazilian Journal of Otorhinolaryngology 84 448-452 (https://doi.org/10.1016/j. bjorl.2017.05.005).

Cradic KW, Milosevic D, Rosenberg AM, Erickson LA, McIver B \& Grebe SK 2009 Mutant BRAF (T1799A) can be detected in the blood of papillary thyroid carcinoma patients and correlates with disease status. Journal of Clinical Endocrinology \& Metabolism 94 5001-5009 (https://doi.org/10.1210/jc.2009-1349).

Dekker BL, Van der Horst-Schrivers ANA, Sluiter WJ, Brouwers AH, Lentjes EGWM, Heijboer AC, Muller Kobold AC \& Links TP 2019 Clinical applicability of low levels of thyroglobulin autoantibodies as cut off point for thyroglobulin autoantibody positivity. Thyroid $\mathbf{2 9}$ 71-78. (https://doi.org/10.1089/thy.2018.0195).

Ernaga-Lorea A, Hernández-Morhain MC, Anda-Apiñániz E, PinedaArribas JJ, Migueliz-Bermejo I, Eguílaz-Esparza N \& Irigaray-Echarri A 2018 Prognostic value of change in anti-thyroglobulin antibodies after thyroidectomy in patients with papillary thyroid carcinoma. Clinical \& Translational Oncology 20 740-744. (https://doi. org/10.1007/s12094-017-1782-3).

Filetti S, Durante C, Hartl D, Leboulleux S, Locati LD, Newbold K, Papotti MG, Berruti A \& ESMO Guidelines Committee. Electronic address: clinicalguidelines@esmo.org 2019 Thyroid cancer: ESMO Clinical Practice Guidelines for diagnosis, treatment and follow-up $\dagger$.
Annals of Oncology 30 1856-1883. (https://doi.org/10.1093/annonc/ $\mathrm{mdz} 400$ ).

Giovanella L, Imperiali M, Verburg FA \& Trimboli P 2018 Early posttreatment risk stratification of differentiated thyroid cancer: comparison of three high-sensitive Tg assays. European Journal of Endocrinology 178 75-82. (https://doi.org/10.1530/EJE-17-0663).

Giovanella L, Verburg FA, Trimboli P, Imperiali M, Keller F \& Ceriani L 2019 Measuring thyroglobulin in patients with thyroglobulin autoantibodies: evaluation of the clinical impact of BRAHMS Kryptor Tg-minirecovery test in a large series of patients with differentiated thyroid carcinoma. Clinical Chemistry \& Laboratory Medicine 57 1185-1191. (https://doi.org/10.1515/cclm-2018-1390).

Guastapaglia L, Kasamatsu TS, Nakabashi CCD, Camacho CP, Maciel RMB, Vieira JGH \& Biscolla RPM 2020 The role of a new polyclonal competitive thyroglobulin assay in the follow-up of patients with differentiated thyroid cancer with structural disease but low levels of serum thyroglobulin by immunometric and LC-MS/MS methods. Endocrine. (https://doi.org/10.1007/s12020-020-02526-8).

Haddad RI, Nasr C, Bischoff L, Bernet V, Blomain E, Lamki N, Dickson P, Duh QY, Ehya H, Goldner W, et al. 2020 National Comprehensive Cancer Network (NCCN) Clinical Practice Guidelines in Oncology: Thyroid Carcinoma Version 2.2020. (available at: https://www.nccn. org/professionals/physician_gls/pdf/thyroid.pdf)

Haugen BR, Alexander EK, Bible KC, Doherty GM, Mandel SJ, Nikiforov YE, Pacini F, Randolph GW, Sawka AM \& Schlumberger M, et al. 2015 American thyroid association management guidelines for adult patients with thyroid nodules and differentiated thyroid cancer: The American thyroid association guidelines task force on thyroid nodules and differentiated thyroid cancer. Thyroid 26 1-133.

Hoofnagle AN \& Roth MY 2013 Clinical review: improving the measurement of serum thyroglobulin with mass spectrometry. Journal of Clinical Endocrinology \& Metabolism 98 1343-1352. (https:// doi.org/10.1210/jc.2012-4172).

Hsieh CJ \& Wang PW 2014 Sequential changes of serum antithyroglobulin antibody levels are a good predictor of disease activity in thyroglobulin-negative patients with papillary thyroid carcinoma. Thyroid 24 488-493. (https://doi.org/10.1089/ thy.2012.0611).

Jeon MJ, Park JW, Han JM, Yim JH, Song DE, Gong G, Kim TY, Baek JH, Lee JH, Shong YK, et al. 2013 Serum antithyroglobulin antibodies interfere with thyroglobulin detection in fine-needle aspirates of metastatic neck nodes in papillary thyroid carcinoma. Journal of Clinical Endocrinology \& Metabolism 98 153-160. (https://doi. org/10.1210/jc.2012-2369).

Jo K, Kim MH, Lim Y, Jung SL, Bae JS, Jung CK, Kang MI, Cha BY \& Lim DJ 2015 Lowered cutoff of lymph node fine-needle aspiration thyroglobulin in thyroid cancer patients with serum antithyroglobulin antibody. European Journal of Endocrinology $\mathbf{1 7 3}$ 489-497. (https://doi.org/10.1530/EJE-15-0344).

Kim WG, Yoon JH, Kim WB, Kim TY, Kim EY, Kim JM, Ryu JS, Gong G, Hong SJ \& Shong YK 2008 Change of serum antithyroglobulin antibody levels is useful for prediction of clinical recurrence in thyroglobulin-negative patients with differentiated thyroid carcinoma. Journal of Clinical Endocrinology \& Metabolism 93 4683-4689. (https://doi.org/10.1210/jc.2008-0962).

Kushnir MM, Rockwood AL, Roberts WL, Abraham D, Hoofnagle AN \& Meikle AW 2013 Measurement of thyroglobulin by liquid chromatography-tandem mass spectrometry in serum and plasma in the presence of antithyroglobulin autoantibodies. Clinical Chemistry 59 982-990. (https://doi.org/10.1373/clinchem.2012.195594).

Lamartina L, Grani G, Durante C, Borget I, Filetti S \& Schlumberger M 2018 Follow-up of differentiated thyroid cancer - what should (and what should not) be done. Nature Reviews. Endocrinology 14 538-551. (https://doi.org/10.1038/s41574-018-0068-3).

Latrofa F, Ricci D, Montanelli L, Rocchi R, Piaggi P, Sisti E, Grasso L, Basolo F, Ugolini C, Pinchera A, et al. 2012 Lymphocytic thyroiditis (c) 2021 Society for Endocrinology Published by Bioscientifica Ltd. Printed in Great Britain 
on histology correlates with serum thyroglobulin autoantibodies in patients with papillary thyroid carcinoma: impact on detection of serum thyroglobulin. Journal of Clinical Endocrinology \& Metabolism 97 2380-2387. (https://doi.org/10.1210/jc.2011-2812).

Latrofa F, Ricci D, Sisti E, Piaggi P, Nencetti C, Marinò M \& Vitti P 2016 Significance of low levels of thyroglobulin autoantibodies associated with undetectable thyroglobulin After thyroidectomy for differentiated thyroid carcinoma. Thyroid 26 798-806. (https://doi. org/10.1089/thy.2015.0621).

Lee JC, Zhao JT, Clifton-Bligh RJ, Gill A, Gundara JS, Ip JC, Glover A, Sywak MS, Delbridge LW, Robinson BG, et al. 2013 MicroRNA-222 and microRNA-146b are tissue and circulating biomarkers of recurrent papillary thyroid cancer. Cancer 119 4358-4365. (https:// doi.org/10.1002/cncr.28254).

Lee ZJO, Eslick GD \& Edirimanne S 2020 Investigating antithyroglobulin antibody as a prognostic marker for differentiated thyroid cancer: A meta-analysis and systematic review. Thyroid 30 1601-1612. (https:// doi.org/10.1089/thy.2019.0368).

Lupoli GA, Okosieme OE, Evans C, Clark PM, Pickett AJ, Premawardhana LD, Lupoli G \& Lazarus JH 2015 Prognostic significance of thyroglobulin antibody epitopes in differentiated thyroid cancer. Journal of Clinical Endocrinology \& Metabolism 100 100-108. (https://doi.org/10.1210/jc.2014-2725).

Martins-Costa MC, Maciel RMB, Kasamatsu TS, Nakabashi CCD, Camacho CP, Crispim F, Ikejiri ES, Mamone MCO, Andreoni DM \& Biscolla RPM 2017 Clinical impact of thyroglobulin (Tg) and Tg autoantibody $(\mathrm{TgAb})$ measurements in needle washouts of neck lymph node biopsies in the management of patients with papillary thyroid carcinoma. Archives of Endocrinology \& Metabolism 61 108-114. (https://doi.org/10.1590/2359-3997000000241).

Matrone A, Latrofa F, Torregrossa L, Piaggi P, Gambale C, Faranda A, Ricci D, Agate L, Molinaro E, Basolo F, et al. 2018 Changing trend of thyroglobulin antibodies in patients With differentiated thyroid cancer treated With total thyroidectomy Without ${ }^{131}$ I ablation. Thyroid 28 871-879. (https://doi.org/10.1089/thy.2018.0080).

Netzel BC, Grebe SK, Carranza Leon BG, Castro MR, Clark PM, Hoofnagle AN, Spencer CA, Turcu AF \& Algeciras-Schimnich A 2015 Thyroglobulin ( $\mathrm{Tg}$ ) testing revisited: $\mathrm{Tg}$ assays, $\mathrm{TgAb}$ assays, and correlation of results With clinical outcomes. Journal of Clinical Endocrinology \& Metabolism 100 E1074-E1083. (https://doi. org/10.1210/jc.2015-1967).

Pacini F, Basolo F, Bellantone R, Boni G, Cannizzaro MA, De Palma M, Durante C, Elisei R, Fadda G, Frasoldati A, et al. 2018 Italian consensus on diagnosis and treatment of differentiated thyroid cancer: joint statements of six Italian societies. Journal of Endocrinological Investigation 41 849-876. (https://doi.org/10.1007/s40618-018-0884-2).

Reverter JL, Rosas-Allende I, Puig-Jove C, Zafon C, Megia A, Castells I, Pizarro E, Puig-Domingo M \& Granada ML 2020 Prognostic significance of thyroglobulin antibodies in differentiated thyroid cancer. Journal of Thyroid Research 2020 8312628. (https://doi. org/10.1155/2020/8312628).

Ritter A, Mizrachi A, Bachar G, Vainer I, Shimon I, Hirsch D, DikerCohen T, Duskin-Bitan H \& Robenshtok E 2020 Detecting recurrence following lobectomy for thyroid cancer: role of thyroglobulin and thyroglobulin antibodies. Journal of Clinical Endocrinology \& Metabolism 105. (https://doi.org/10.1210/clinem/dgaa152).

Rosario PW, Maia FF, Fagundes TA, Vasconcelos FP, Cardoso LD \& Purisch S 2004a Antithyroglobulin antibodies in patients with differentiated thyroid carcinoma: methods of detection, interference with serum thyroglobulin measurement and clinical significance. Arquivos Brasileiros de Endocrinologia e Metabologia 48 487-492. (https://doi.org/10.1590/s0004-27302004000400008).
Rosario PW, Fagundes TA \& Purisch S 2004b Treatment of papillary microcarcinoma of the thyroid. Arquivos Brasileiros de Endocrinologia e Metabologia 48 855-860. (https://doi.org/10.1590/s000427302004000600012)

Rosario PW, Carvalho M, Mourão GF \& Calsolari MR 2016 Comparison of antithyroglobulin antibody concentrations Before and After ablation with ${ }^{131} \mathrm{I}$ as a predictor of structural disease in differentiated thyroid carcinoma patients with undetectable basal thyroglobulin and negative neck ultrasonography. Thyroid 26 525-531. (https://doi. org/10.1089/thy.2015.0445).

Scappaticcio L, Trimboli P, Verburg FA \& Giovanella L 2020 Significance of "de novo" appearance of thyroglobulin antibodies in patients with differentiated thyroid cancer. International Journal of Biological Markers 35 41-49. (https://doi.org/10.1177/1724600820931517).

Shin HJ, Lee HS, Kim EK, Moon HJ, Lee JH \& Kwak JY 2015 A study on serum antithyroglobulin antibodies interference in thyroglobulin measurement in fine-needle aspiration for diagnosing lymph node metastasis in postoperative patients. PLOS ONE 10 e0131096. (https://doi.org/10.1371/journal.pone.0131096).

Spencer C, Petrovic I, Fatemi S \& LoPresti J 2014 Serum thyroglobulin ( $\mathrm{Tg}$ ) monitoring of patients with differentiated thyroid cancer using sensitive (second-generation) immunometric assays can be disrupted by false-negative and false-positive serum thyroglobulin autoantibody misclassifications. Journal of Clinical Endocrinology \& Metabolism 99 4589-4599. (https://doi.org/10.1210/jc.2014-1203).

Spencer CA, Takeuchi M, Kazarosyan M, Wang CC, Guttler RB, Singer PA, Fatemi S, LoPresti JS \& Nicoloff JT 1998 Serum thyroglobulin autoantibodies: prevalence, influence on serum thyroglobulin measurement, and prognostic significance in patients with differentiated thyroid carcinoma. Journal of Clinical Endocrinology \& Metabolism 83 1121-1127. (https://doi.org/10.1210/jcem.83.4.4683).

Sun D, Zheng X, He X, Huang C, Jia Q, Tan J, Zheng W, Li N, Wang P, Wang R, et al. 2020 Prognostic value and dynamics of antithyroglobulin antibodies for differentiated thyroid carcinoma. Biomarkers in Medicine 14 1683-1692. (https://doi.org/10.2217/bmm-2019-0432).

Trimboli P, Zilioli V, Imperiali M \& Giovanella L 2017 Thyroglobulin autoantibodies before radioiodine ablation predict differentiated thyroid cancer outcome. Clinical Chemistry and Laboratory Medicine 55 1995-2001. (https://doi.org/10.1515/cclm-2017-0033).

Verburg FA, Luster M, Cupini C, Chiovato L, Duntas L, Elisei R, FeldtRasmussen U, Rimmele H, Seregni E, Smit JW, et al. 2013 Implications of thyroglobulin antibody positivity in patients with differentiated thyroid cancer: a clinical position statement. Thyroid 23 1211-1225. (https://doi.org/10.1089/thy.2012.0606).

Woeber KA 2016 The significance of thyroglobulin antibodies in papillary thyroid cancer. Endocrine Practice 22 1132-1133. (https:// doi.org/10.4158/EP161367.CO).

Xiao Q, Jia Q, Tan J \& Meng Z 2020 Serum biomarkers for thyroid cancer. Biomarkers in Medicine 14 807-815. (https://doi.org/10.2217/ bmm-2019-0578).

Yin N, Sherman SI, Pak Y, Litofsky DR, Gianoukakis AG \& National Thyroid Cancer Treatment Cooperative Study Group 2020 The de novo detection of anti-thyroglobulin antibodies and differentiated thyroid cancer recurrence. Thyroid 30 1490-1495. (https://doi. org/10.1089/thy.2019.0791).

Zavala LF, Barra MI, Olmos R, Tuttle M, González H, Droppelmann N, Mosso L \& Domínguez JM 2019 In properly selected patients with differentiated thyroid cancer, antithyroglobulin antibodies decline after thyroidectomy and their sole presence should not be an indication for radioiodine ablation. Archives of Endocrinology \& Metabolism 63 293-299. (https://doi.org/10.20945/23593997000000123).

Received in final form 24 February 2021

Accepted 10 March 2021

Accepted Manuscript published online 10 March 2021 https://erc.bioscientifica.com

https://doi.org/10.1530/ERC-21-0012 (c) 2021 Society for Endocrinology Published by Bioscientifica Ltd. Printed in Great Britain 